\title{
Helium Ion Implantation Effects of 9Cr-ODS(Oxide Dispersion Strengthened) Steel
}

Chenyang $\mathrm{Lu}^{1,2}$, Zheng $\mathrm{Lu}^{2}$, Gang $\mathrm{Yu}^{1}$ and Lumin Wang ${ }^{1}$

1.Department of Nuclear Engineering and Radiological Science, University of Michigan, Ann Arbor, MI 48109, USA.

2. Key Laboratory for Anisotropy and Texture of Materials, Ministry of Education, Northeastern University, Shenyang 110819, China.

The oxide dispersion strengthened (ODS) reduced activation ferritic/martensitic(RAFM) steels are among the most popular candidate materials for the future fusion reactor because of their excellent swelling resistance and higher operating temperature. Compared to the conventional RAFM steel, high density Y-Ti-O rich nanoclusters (NC)/precipitates, dislocations and sub-micron grain size in ODS steels increase the operating temperature from $823 \mathrm{~K}$ to $923 \mathrm{~K}[1]$, and provide a great number of trap sites for transmutant helium $(\mathrm{He})$ and radiation-induced defects[2].One important performance properties of ODS steel is its capability to absorb helium. High concentration helium will be dispersed in the structure materials in the fusion reactor. The high density nanoclusters, dislocations, grain boundaries are helpful to decrease the size of helium bubble, minimize volume swelling and avoid helium embrittlement. In this study, $400 \mathrm{keV}$ helium ions were implanted in to a 9Cr-ODS steel to study the helium bubble distribution in the steel.

The 9Cr-ODS steel was produced by mechanical alloying and spark plasma sintering(SPS) at Northeastern University in China. The nominal composition of the steel is Fe-9Cr-1.5W-0.4Mn-0.1Ta$0.2 \mathrm{~V}-0.3 \mathrm{Ti}-0.3 \mathrm{Y}_{2} \mathrm{O}_{3}$ (wt.\%). $\mathrm{He}^{+}$ion implantation was carried out using the $400 \mathrm{kV}$ NEC ion implanter at MIBL(Michigan Ion Beam Laboratory), University of Michigan. The samples were implanted at $673 \mathrm{~K}$ to an ion fluence of $4 \times 10^{17} \mathrm{He}^{+} / \mathrm{cm}^{2}$. In order to observe the depth distribution of implanted He in cross-section, focused ion beam (FIB) lift-out method was adopted for the preparation of TEM specimen by using a FEI Nova Nanolab Dualbeam. STEM analysis was conducted using a 200kV JEOL 2100F spherical aberration (Cs)-corrected Analytical Electron Microscope, including high angle annual dark field(HAADF) and bright field-STEM imaging techiniques. Line scan chemical analysis was performed using Energy-dispersive X-Ray Spectroscopy (EDS) in the STEM mode.

The depth distribution of helium bubbles in the implanted sample is shown in Fig.1. The helium bubbles are shown as white dots in the BF-STEM image, Fig.1(a), and as black dots in HAADF image because of the lower mass, Fig.1(b). The computer simulated damage and He concentration profiles are overlaid on the HAADF image, showing a perfect matching with the experiment results. The maximum bubble diameter in the peak He concentration region (19dpa, 20 at. $\%$ helium) is only $8.3 \mathrm{~nm} \pm 2 \mathrm{~nm}$. The HAADF image and line scanning result of a $\mathrm{Cr}-\mathrm{Mn}-\mathrm{O}$ rich precipitate are shown in Fig2(a) and Fig.2(b), respectively. Obviously, helium bubbles in the $\mathrm{Cr}-\mathrm{Mn}-\mathrm{O}$ rich precipitate $(2 \mathrm{~nm} \pm 0.5 \mathrm{~nm})$ are much smaller than bubbles in the ferritic matrix. Generally, Y-Ti-O precipitates, dislocations and grain boundaries are considered as the perfect trap sites for decreasing the helium bubble size in ODS steel. But in this case, the $\mathrm{Cr}-\mathrm{Mn}-\mathrm{O}$ rich precipitate also showed an amazing ability to disperse helium bubbles. The detailed structure of this precipitate is still under investigation.

[1] G.R. Odette, M.J. Alinger, B.D.Wirth, Annu. Rev. Mater. Res. 38 (2008) 471-503.

[2] S. Ukai, S. Ohtsuka, Eng. Mater. 2 (2007) 26-35.

[3] This research is supported by the National Natural Science Foundation of China (50971033 and 91026013), National Basic Research Program of China (2011CB610405). 


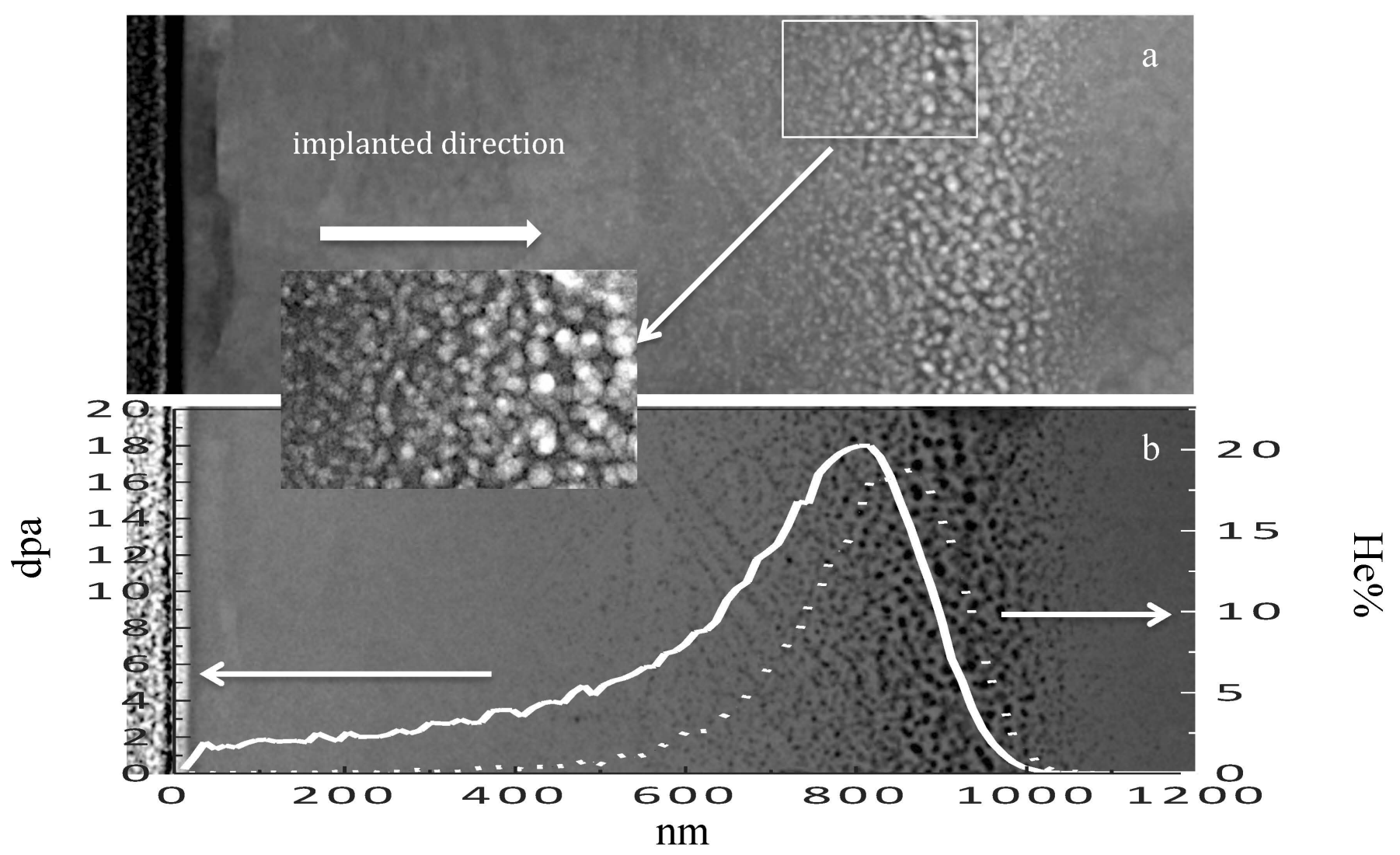

Figure 1. Depth distribution of helium bubble in a 9Cr-ODS steel implanted with $400 \mathrm{keV} \mathrm{He}^{+}$ions at $673 \mathrm{~K}$ to $4 \times 10^{17} \mathrm{He}^{+} / \mathrm{cm}^{2}$.(a) STEM-Bright Field image. (b) HAADF image overlaid with predicted damage and He concentration profiles calculated by the SRIM code.
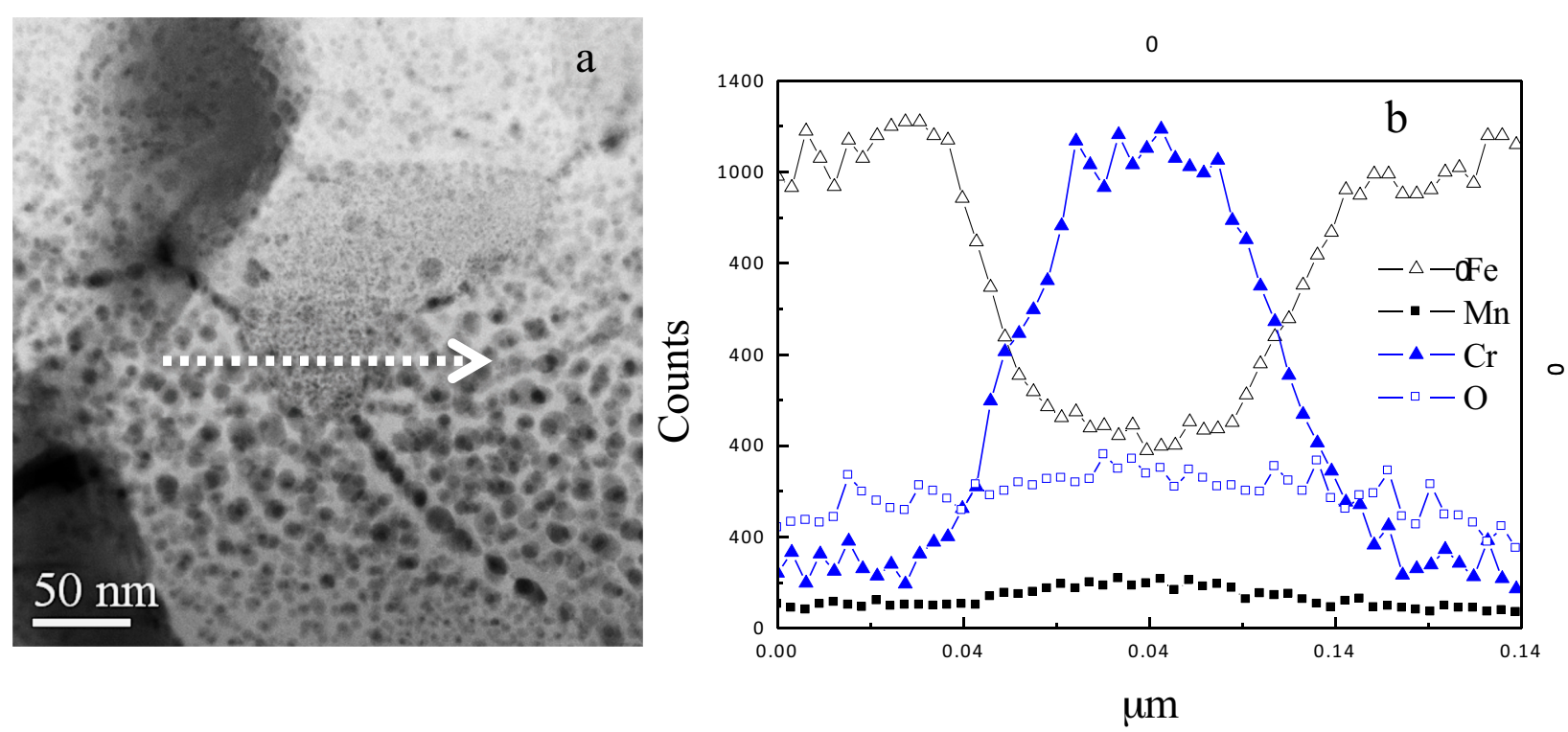

Figure 2. (a) HAADF image of the helium bubbles in a Cr-Mn-O rich precipitate. (b) Result of an EDS line scan across the length of the arrow in Fig. 2(a) of the $\mathrm{Cr}-\mathrm{Mn}-\mathrm{O}$ rich precipitate. 